\title{
EFEITOS DA EXONERAÇÃO DO DEVEDOR DO SALDO REMANESCENTE NA ALIENAÇÃO FIDUCIÁRIA COM A ADVENTO DA LEI № 10.931/2004
}

\section{EFFECTS OF THE EXONERATION OF THE DEBTOR FROM THE REMAINING BALANCE IN THE SECURED TRANSACTIONS WITH THE ADVENT OF BRAZILIAN ACT 10.931/2004}

\begin{abstract}
ALEXANDRE FERREIRA DE ASSUMPÇÃO ALVES
Doutor em Direito Civil pela UERJ. Professor Associado de Direito Comercial nas Faculdades de Direito da Universidade Estadual do Rio de Janeiro - UERJ da Universidade Federal do Rio de Janeiro - UFRJ. Docente permanente do PPGD da UERJ, linha de pesquisa Empresa e Atividades Econômicas.
\end{abstract}

\section{MARCIA CARLA PEREIRA RIBEIRO}

Doutora em Direito das Relações Sociais pela UFPR. Professora Titular de Direito Societário da PUCPR e Professora Associada de Direito Comercial na UFPR. Docente permanente do PPGD da PUCPR e UFPR.

\section{RESUMO}

A alienação fiduciária é uma modalidade contratual de garantia inicialmente voltada à compra de bens móveis, mas que foi estendida à aquisição de bens imóveis, como estratégia alternativa a programas habitacionais voltados à promoção ao acesso a bens imóveis para habitação. A disciplina da alienação fiduciária aplicada aos bens imóveis estabeleceu a exoneração do devedor pelo valor residual à venda do imóvel, na hipótese de execução da garantia, benefício introduzido para o contexto de aquisição de bens imóveis voltados às famílias de baixa renda. A Lei № 10.931/2004 estendeu a possibilidade desta forma de garantia a qualquer obrigação. Utilizando-se 
do método indutivo de análise bibliográfica e valendo-se de algumas ferramentas da Nova Economia Institucional, o artigo aponta para a defasagem entre o contexto que conduziu a elaboração normativa comentada e sua ampliação para a aquisição geral de bens, inclusive para bens imóveis, independente do valor, quando garantida por alienação fiduciária. Analisa a doutrina, assim como as normas incidentes, projeto de reforma legislativa e o teor da súmula que disciplina parcialmente a matéria, para concluir que a pretensão normativa, quando da edição da norma, tem seus objetivos ameaçados pela exagerada extensão do efeito de desoneração do devedor frente ao credor garantido pela alienação fiduciária.

PALAVRAS-CHAVE: Alienação Fiduciária em Garantia; Eficiência; Desoneração geral; Devedor; Perspectivas.

\section{ABSTRACT}

The secured transaction is a contractual modality of guarantee initially focused on the purchase of movable property, but extended to the acquisition of real estate, as an alternative strategy to housing programs aimed at promoting access to real estate for housing. The Brazilian law of secured transaction applied to real estate established the exemption of the borrower by the residual value of collateral sale, in case of borrower defaults on the loan, a benefit introduced for the context of acquisition of real estate for low income families. The Brazilian act n. 10.931/2004 extended this form of secured transaction to all kind of obligation. Using the inductive method of bibliographical analysis and using some tools of the New Institutional Economy, the article points to the discrepancy between the context that led to the law edition and its extension to the general acquisition of real estate with a security agreement. It analyzes the doctrine, as well as the incident acts, draft legislative reform and the content of the law that partially disciplines the matter, to conclude that the normative pretension, when the rules were published, has its objectives threatened by the exaggerated extension of the tax relief effect of the debtor against the secured creditor. 
KEYWORDS: Secured transactions; Efficiency; General disclaimer; Debtor; Perspectives.

\section{INTRODUÇÃO}

Com o acelerado processo de urbanização e aumento da concentração da população nas cidades, a partir da década de 50 do século anterior, o setor imobiliário brasileiro revelou-se um ramo próspero e em constante desenvolvimento que exigiu investimentos cada vez mais vultosos. Contudo, para que tais investimentos fossem atrativos aos aplicadores de poupança, era preciso thes oferecer segurança nos negócios jurídicos empresariais capaz de efetivar o retorno eficaz do capital aplicado, com a redução dos custos de transação e incertezas futuras.

As distorções e erros na política econômica em relação ao setor imobiliário voltado à população de baixa renda, através de sucessivos diplomas legais na década de 1980, aliada a uma inflação fora de controle, acarretou a quase "falência" do setor. Para tentar revigorá-lo e dar novo fomento a este segmento, em 20 de novembro de 1997, foi promulgada a Lei № 9.514, que dispõe sobre o Sistema de Financiamento Imobiliário (SFI). Essa lei teve como principal objetivo inserir no ordenamento jurídico a alienação fiduciária em garantia de financiamentos para construção ou aquisição de imóveis.

A alienação fiduciária de imóveis surgiu como nova forma de garantia real, capaz de dar ao credor maior segurança e celeridade na recuperação de seu crédito em caso de inadimplemento do devedor. A alienação fiduciária é vantajosa para o credor, quando comparada em seu método de execução a outras garantias reais como a hipoteca, porque essa não autoriza a venda extrajudicial do imóvel. Assim, o instituto acabou por trazer maior solidez ao mercado imobiliário ao permitir o fechamento do ciclo essencial que garante, ao mesmo tempo, mais opções de crédito aos consumidores para aquisição de bens financiados e maior segurança para os construtores.

Inicialmente, utilizando-se de método indutivo e pesquisa dos tipos bibliográfica e documental, serão apresentadas as principais razões motivadoras da 
introdução da alienação fiduciária de imóveis e a legislação posterior. Neste diapasão, a Exposição de Motivos do Projeto de Lei oㅜ 3.242/97, convertido na Lei oㅡ 9.514/97, deixa claro que o governo do presidente Fernando Henrique Cardoso, tinha "o compromisso com o atendimento da demanda por moradias, bem como a geração de emprego e o crescimento econômico em bases autossustentáveis". A justificativa para a introdução da alienação fiduciária de imóveis foi a diminuição de unidades residenciais financiadas pelo Sistema Nacional de Habitação nos últimos anos, diante do enfraquecimento das garantias apresentadas pelos pretendentes à aquisição da casa própria.

Já na primeira década do século atual, para atender ao dinamismo do mercado, a Lei no 10.931, de 02 de agosto de 2004, ampliou o campo de aplicação da alienação fiduciária, possibilitando que as instituições financeiras a utilizassem como forma de garantir obrigações em geral. Desta forma, o legislador afastou-se do inicialmente pretendido no momento de criação do referido instituto.

Em segundo momento, o trabalho discorrerá sobre as discrepâncias entre o objetivo inicial da Lei oㅜ 9.514/97 e os termos da Lei oㅡ 10.931/2004, sobretudo no tangente ao método utilizado para execução da dívida em caso de inadimplência do fiduciante. Exemplo prático é a aplicabilidade do artigo 27 , $\S 5^{\circ}$, a qualquer contrato de alienação fiduciária de imóveis. Este dispositivo institui a completa quitação da dívida ainda que o valor obtido pelo imóvel seja inferior ao débito existente no segundo leilão.

Sob o pensamento motivador da Lei ํㅜ 9.514/97, que adota como parte vulnerável do financiamento imobiliário o devedor, a disposição presente no $\S 5^{\circ}$ do artigo 27 só se justifica ao mostrar seu caráter protetivo no âmbito do Sistema Financeiro de Habitação. Porém, com o advento da Lei no 10.931/04, especialmente o art. 51, a disposição do parágrafo $5^{\circ}$ do art. 27 da Lei no 9.514/97 deixou de ser protetiva ao devedor e passou a privilegiá-lo de maneira indevida, em detrimento dos direitos do credor, sem considerar a vulnerabilidade em concreto.

Também será examinado que a alteração no panorama legislativo do instituto e a problemática causada foram progressivamente percebidos pela doutrina e pelo legislativo brasileiro. Desta forma, o debate recairá sobre a possibilidade de execução do saldo remanescente, visando a demonstrar a incongruência normativa atualmente 
vigente. Além disso, serão comentados os Projetos de Lei oํ 1.070/2007 e ํo 6.525/2013, apresentados na Câmara dos Deputados para alterar o parágrafo $5^{\circ}$ do artigo 27.

Será demonstrado que a previsão da possibilidade de o devedor responder

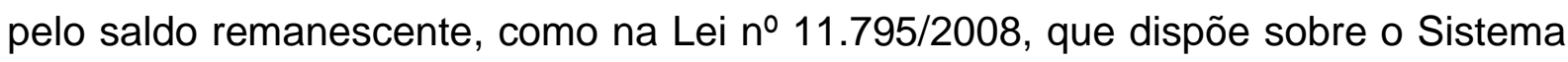
de Consórcios, ou ainda, o cabimento de cobrança por meio de ação monitória do saldo remanescente oriundo de venda extrajudicial de bem alienado fiduciariamente, consubstanciada na Súmula 384 do STJ, não solucionam o problema.

Por fim, encerra-se o trabalho com uma análise dos potenciais impactos da extensão imotivada a qualquer fiduciante do beneplácito da quitação do débito pelo credor, sob a ótica da Nova Economia Institucional. Busca-se demonstrar que a elaboração normativa algumas vezes poderá afastar-se da pretensão que originou a sua própria criação, por meio da produção de efeitos indesejáveis ou insuficientes, quando então, a opção pela alteração da norma é medida que se impõe, em proveito da eficiência econômica e social.

\section{A INTRODUÇÃO DA ALIENAÇÃO FIDUCIÁRIA EM GARANTIA NO DIREITO BRASILEIRO E A AMPLIAÇÃO DA UTILIZAÇÃO DO INSTITUTO COM O ADVENTO DA LEI № 10.931/2004}

A alienação fiduciária é reconhecida como modalidade contratual que assegura ao credor o cumprimento da obrigação assumida pelo devedor quando da aquisição de determinado bem, mediante financiamento do credor, em praticamente todas as economias contemporâneas. É também corrente o entendimento de que as formas de garantia asseguradas pela lei tendem a consolidar um ambiente econômico de oferta de crédito menos custoso ${ }^{1}$.

Para se compreender a função econômica do contrato, é interessante observar que a origem da alienação fiduciária e da propriedade fiduciária

\footnotetext{
${ }_{1}^{1}$ Sobre o instituto da alienação fiduciária no direito anglo-saxão (Secured Transactions), cf. nos E.U.A: SHUPACK, 2018; GILMORE, 2011. Na Europa e em normativas internacionais: BEALE, 2008
} 
compartilham do pressuposto de que o adquirente assume uma função de gestão de bem cuja titularidade última pertence ao alienante/financiador ${ }^{2}$

A alienação fiduciária em garantia de bem imóvel foi implementada no ordenamento jurídico brasileiro afim de conferir maior solidez e segurança ao Sistema Financeiro de Habitação (SFH) e para proporcionar seu reerguimento em face da intensa crise ao longo de suas duas primeiras décadas de existência.

Ainda que brevemente, cabe um escorço histórico do SFH para melhor compreensão de sua reformulação em 1997 com a Lei no 9.514.

\title{
2.1 ANTECEDENTES DA LEI № 9.514/1997
}

O Sistema Financeiro de Habitação foi criado pela Lei № 4.380/64 com o objetivo de formular a política nacional de habitação e planejamento territorial, pela coordenação da ação dos órgãos públicos e orientação à iniciativa privada. $O$ fito do SFH era estimular a construção de habitações de interesse social e o financiamento da aquisição da casa própria, especialmente pelas classes da população de menor renda (art. $\left.1^{\circ}\right)$.

O viés social do SFH é evidenciado, sobretudo, pelo artigo $4^{\circ}$ da Lei $n^{\circ}$ 4.380/64 ao elencar as prioridades para alocação dos recursos:

\begin{abstract}
Art. 4ำ Terão prioridade na aplicação dos recursos: I - a construção de conjuntos habitacionais destinados à eliminação de favelas, mocambos e outras aglomerações em condições sub-humanas de habitação; II - os projetos municipais ou estaduais que com as ofertas de terrenos já urbanizados e dotados dos necessários melhoramentos, permitirem o início imediato da construção de habitações; III- os projetos de cooperativas e outras formas associativas de construção de casa própria; IV- os projetos da iniciativa privada que contribuam para a solução de problemas habitacionais; $\mathrm{V}$ - a construção de moradia a população rural.
\end{abstract}

A partir do rol de prioridades elencadas pelo supracitado artigo, torna-se evidente que a intenção do legislador no momento de criação do SFH era restringir seu âmbito à construção de moradias, limitando sua influência dentro de um determinado padrão destinado à população de baixa renda e poder aquisitivo.

\footnotetext{
2 Sobre a origem da relação fiduciária e também com relação ao caráter diferente que lhe é atribuído pelo Direito Civil do Quebec: CUMYN, 2013.
} 
Embora o SFH, no momento de seu advento, tenha se mostrado promissor e, até 1997, tenha financiado cerca de 6 milhões de unidades residenciais dentro dos moldes estabelecidos pela legislação que o rege, com o passar dos anos e com a grave crise inflacionária que atingiu o país, o Sistema foi sofrendo crescente esgotamento. Com isso, à época, o SFH já não financiava nem um décimo dos imóveis necessários para suprir a demanda por moradias anualmente ${ }^{3}$.

Parte dessa crise deveu-se ao fato de que o Sistema possuía duas fontes principais de recursos, quais sejam a caderneta de poupança e o Fundo de Garantia por Tempo de Serviço. Ambas as fontes se mostraram insuficientes para assegurar os financiamentos a serem obtidos perante o Banco Nacional de Habitação (BNH).

Conforme consta da Exposição de Motivos do Projeto de Lei no 3.242/97, convertido na Lei no 9.514/97:

\begin{abstract}
Por seus efeitos negativos sobre a renda e o emprego, a aceleração inflacionária, somada as sucessivas medidas que acentuaram 0 descompasso entre os reajustes das prestações e dos saldos devedores, acabou por desequilibrar o sistema de modo grave, senão irremediavelmente. Do lado das fontes de recursos, a caderneta de poupança passou a enfrentar a competição cada vez mais acirrada da indústria de fundos de investimento, apresentando um comportamento menos dinâmico e mais volátil. Paralelamente, os novos depósitos do FGTS tornaram-se insuficientes para atender aos saques e ainda fazer novas aplicações.
\end{abstract}

Como agravante de todo o cenário de visíveis desgastes, em 16 de junho de 1967, havia sido criado o Fundo de Compensação de Variações Salariais (FCVS), mediante a publicação da Resolução no 25 , do Conselho de Administração do BNH.

O FCVS tinha por finalidade, dentre outras, assumir, em nome do mutuário, os descontos concedidos nas liquidações antecipadas, nas transferências de contratos de financiamento habitacional e nas renegociações com extinção da reponsabilidade do fundo, além de cobrir o saldo devedor de financiamento imobiliário, total ou parcial, em caso de morte ou invalidez permanente do mutuário.

Ocorre que, em virtude da crise inflacionária nas décadas de 70 e 80 , o governo federal passou a conceder sucessivos benefícios aos mutuários do BNH para impedir que as prestações previstas nos contratos de financiamento fossem

\footnotetext{
${ }^{3}$ Dados extraídos da Exposição de Motivos do Projeto de Lei no 3.242, de 1997, apresentado à Câmara dos Deputados em 12 de junho de 1997.
} 
majoradas. Com isso, o FCVS que, inicialmente, havia sido criado com o fim de liquidar eventuais saldos devedores residuais, passou a assumir dívidas muito superiores ao seu fluxo de caixa, como se percebe com e edição dos diplomas a seguir.

O Decreto-Lei ำ 2.164/1984 institui incentivo financeiro para os adquirentes de moradia própria pelo SFH através de emissão de bônus de emissão do BNH, variável de $10 \%$ a $25 \%$. O diploma estabeleceu que, para os contratos firmados a partir daquela data, o FCVS ressarciria os saldos devedores em parcela única.

O Decreto-Lei oㅡ 2.291/86 e o Decreto-Lei ํo 2.406/88 foram responsáveis pela concessão de novos subsídios, sobrecarregando ainda mais o já desgastado FCVS. Em 18 de setembro de 1988, além de todos os subsídios supramencionados, o Decreto-Lei no 2.476 dispôs que o FCVS passasse a garantir o equilíbrio do seguro habitacional do SFH em todo o território nacional.

Por fim, a Lei o 8.004/90, ao conceder novos subsídios, determinou que o Fundo quitaria os saldos de sua responsabilidade no prazo de 10 anos, após o cumprimento de 3 anos de carência a contar daquela data.

É importante frisar que, embora o pagamento dos saldos oriundos do FCVS tenha sido aditado por diversas vezes, todos os normativos que estabeleceram prazos para ressarcimento desses saldos asseguraram aos credores o reajuste mensal das dívidas. Foi adotado o mesmo índice utilizado para corrigir depósitos de poupança e juros adicionais calculados à taxa do contrato original.

A Lei ํㅜ 10.150/2000, em seu art. 1ㅜ, trouxe desfecho ao FCVS, dispondo sobre a novação de suas dívidas junto às instituições financiadoras, a ser celebrada entre cada credor e a União. Ficou estabelecido um prazo de até 30 anos, contado a partir de $1^{\circ}$ de janeiro de 1997 , com os 8 primeiros anos de carência para pagamento dos juros e os 12 primeiros de carência para pagamento do principal.

O BNH, por sua vez, foi extinto pelo Decreto-lei o 2.291/86, tendo sido incorporado à Caixa Econômica Federal. O BNH tinha uma dívida de aproximadamente $R \$ 2,5$ bilhões, passivo este incorporado pela Caixa Econômica 
Federal, juntamente com as obrigações de gestão do Fundo de Garantia por Tempo de Serviço (art. 1으, $\left.\S 1^{\circ}\right) .^{4}$

Diante deste cenário, com a sobrecarga das fontes de recursos anteriormente utilizadas para fomentar os financiamentos, era preciso encontrar novas formas de garantir o pagamento dos créditos que fossem fornecidos no âmbito do SFH, além de reforçar e retomar a credibilidade do setor imobiliário que se encontrava abalada.

Tendo a experiência de crise anterior como justificativa, o Projeto de Lei no 3.432/1997, convertido na Lei no 9.514/97, foi apresentado na Câmara dos Deputados pelo Poder Executivo para que a alienação fiduciária em garantia de bem imóvel fosse instituída e suprisse grave lacuna no sistema de garantias do SFH.

\subsection{AMPLIAÇÃO DAS OPERAÇÕES GARANTIDAS POR ALIENAÇÃO FIDUCIÁRIA DE IMÓVEIS COM O ADVENTO DA LEI № 10.931/2004}

Se no momento de edição da Lei no 9.514/97 possibilitou-se que a alienação fiduciária fosse utilizada como forma de garantir operações de financiamento imobiliário para dar maior celeridade e segurança a eventuais execuções de dívidas e, portanto, maior credibilidade ao setor, com o tempo o instituto mostrou-se campo fértil e capaz de ter sua utilização estendida a outros setores. Nesse sentido, em 2 de agosto de 2004, a Lei № 10.931 voltou a tratar da alienação fiduciária em garantia de bem imóvel; contudo, dessa vez, com novo objetivo e roupagem.

A supracitada Lei tinha como objetivo, dentre outros, dispor sobre o patrimônio de afetação em incorporações mobiliárias. Enquanto a Lei № 9.514/97 tratava da alienação fiduciária como forma de garantir que os financiamentos para aquisição da casa própria fossem quitados, seja pelo pagamento regular das parcelas e juros, seja pela execução do bem financiado, a Lei ㄲo 10.931/04 veio dar à alienação fiduciária nova função. $O$ artigo 51 desse diploma estabeleceu que:

\footnotetext{
${ }^{4}$ Para Christopher Peterson, nos E.U.A. foram diversas as iniciativas nas décadas de 30 e 40 de criação de instituições governamentais que pudessem incrementar a oferta de crédito voltado à construção civil. Por outro lado, a crise do subprime foi uma das consequências do excesso de operações secundárias relativas ao mercado de imóveis, acompanhada da cultura não intervencionista daquele país. PETERSON, 2007.
} 


\begin{abstract}
Art. 51. Sem prejuízo das disposições do Código Civil, as obrigações em geral também poderão ser garantidas, inclusive por terceiros, por cessão fiduciária de direitos creditórios decorrentes de contratos de alienação de imóveis, por caução de direitos creditórios ou aquisitivos decorrentes de contratos de venda ou promessa de venda de imóveis e por alienação fiduciária de coisa imóvel.
\end{abstract}

A partir de então, a alienação fiduciária de bem imóvel vem sendo utilizada como instrumento de garantia de qualquer obrigação, não estando mais jungida ao Sistema de Financiamento Imobiliário (SFI). Além disso, o referido artigo trouxe a possibilidade de o devedor fiduciante não permanecer mais vinculado à mesma pessoa (física ou jurídica.). Destarte, o bem alienado fiduciariamente em garantia pode ser tanto de propriedade do fiduciante quanto de terceiro garantidor da obrigação do fiduciante.

Sem embargo, a parte tocante ao presente estudo não é a possibilidade de aplicação da alienação fiduciária em garantia de bem imóvel para função diversa da primordialmente concebida no âmbito do SFI. O relevante a ser ressaltado não é a mudança da aplicabilidade do instituto, mas sim a mudança de intenção presente.

No SFH, o objetivo do legislador era sobretudo social, pois o direito à moradia está insculpido como direito social no art. 6ำ da Constituição Federal. Portanto, o Estado em sua função de garantidor, de provedor do mínimo essencial à vida com dignidade à pessoa humana, concebeu o Sistema com o desiderato de que este fosse capaz de suprir a crescente demanda por moradias e de sanar as já existentes distorções.

A mens legis, ou seja, a real intenção trazida pela legislação editada à época, tinha um viés totalmente socializador, visando à proporcionar a inserção de determinadas camadas da população antes excluídas de um nicho selecionado e restrito proprietário de imóveis próprios, não por meio de um tratamento isonômico, mas sim mediante a previsão de medidas compensatórias (no caso a isenção de pagamento de eventual valor residual). Desta forma, o instituto da alienação fiduciária em garantia de bem imóvel, quando concebido como engrenagem na máquina que movia o SFH, direcionava toda a sua funcionalidade a um fim de caráter socioeconômico. 
Com o advento da Lei № 10.931/04, o legislador se utiliza do instituto da alienação fiduciária em garantia de bem imóvel como fonte de garantia para operações de todo o gênero, podendo essas serem celebradas entre partes paritárias ou não (considerando-se as figuras do credor e devedor), sob uma ótica social ou meramente financeira. Isto tem impacto direto na assimetria ou simetria de informações entre as partes e, por conseguinte, na existência ou não de vulnerabilidade do devedor.

Ocorreu, portanto, uma mudança não apenas na aplicação da alienação fiduciária de bem imóvel, mas também na sua função da garantia ao financiamento habitacional e na nova percepção de vulnerabilidade presumida entre as partes do contrato, independentemente do perfil do contratante.

Assim sendo, até mesmo nos contratos empresariais ("as obrigações em geral"), em que não se presume a vulnerabilidade nem assimetria de informações entre as partes, passam a incidir as disposições da Lei ํㅜ 9.514/97. Com isso, nesse novo cenário econômico, ficou alterada a concepção legislativa originária para a alienação fiduciária de imóveis, mas sem uma análise do alcance e aplicação de certas disposições normativas, em especial o parágrafo $5^{\circ}$ do art. 27 da Lei $n^{\circ}$ 9.514/97.

\subsection{A VULNERABILIDADE DO FIDUCIANTE NO CONTEXTO DA ALIENAÇÃO FIDUCIÁRIA DE IMÓVEIS}

Tanto pelo histórico da criação e dos objetivos do SFH e da Exposição do Motivos ao $\mathrm{PL}$ no $3.242 / 97$, percebe-se que o legislador intentou assegurar a tutela ao mutuário, visivelmente hipossuficiente - técnica, econômica e juridicamente - diante de instituições financeiras, construtoras e demais entes do mercado imobiliário que ocupam o polo contrário, por meio de um mecanismo compensatório, a dispensa de pagamento do valor residual.

Diante do caráter protecionista do Estado em relação às famílias de baixa renda e com o fito de proporcionar a construção de moradias dignas e suficientes para atender a demanda populacional em crescimento, nada mais coerente que 
estabelecer mecanismos que pudessem compensar a desigualdade dos potenciais compradores.

Não obstante, a possibilidade de aplicação da alienação fiduciária de bem imóvel foi ampliada pelo artigo 51 da Lei № 10.931/04, podendo, hodiernamente, garantir quaisquer obrigações. Com essa ampliação, passou a não ser mais possível afirmar que as partes do contrato, credor e devedor, encontram-se em patamares desiguais.

Não há, assim, como se estabelecer a vulnerabilidade do devedor como uma constante em todas as operações garantidas por alienação fiduciária em garantia de bem imóvel isentas de pagamento do valor residual. A operação de crédito pode, a partir de então, ser realizada entre quaisquer partes capazes (empresários ou não) e não apenas dentro dos limites traçados pelo SFH.

Ao estabelecer, no artigo 51 da Lei no 10.931/04, que quaisquer obrigações poderiam ser garantidas pelo instituto da alienação fiduciária em garantia de bem imóvel, o legislador acabou por criar uma incongruência enorme com o restante da legislação em vigor sobre o tema e muitos dos dispositivos que serviam para essa manutenção acabaram por assumir viés diverso e passaram a ser os geradores da desigualdade contratual.

É compreensível que o legislador tenha pretendido compensar a vulnerabilidade do polo mais fraco da relação contratual, o que se depreende da exposição de motivos do projeto que deu origem à Lei oㅡ 9.514/97. Porém, essa compensação só faz sentido se, de fato, no caso concreto houver um sujeito que necessite de proteção especial.

Se a opção legislativa é de compensar desigualdades, os benefícios dispostos devem ser disponibilizados apenas àqueles realmente vulneráveis em sua posição contratual e ainda restritos aos fins habitacionais. Não há que se compreender como vulnerável quem financia imóvel cujo preço excede o valor correspondente ao padrão de moradia da população economicamente desprivilegiada, o que sugeriria, por exemplo, que a isenção de pagamento do valor residual estivesse condicionada em Lei a determinados negócios, atrelados, por exemplo, a faixa de preço ou renda do adquirente. 
Por não ter havido qualquer alteração das disposições da legislação especial sobre alienação fiduciária de imóveis com o advento da Lei ํo 10.931/2004, criou-se um privilégio totalmente incompatível ao pretendido inicialmente ao fiduciante, ao se pretender sua exoneração do restante do débito na situação prevista no art. 27, §5으, da Lei oㅜ 9.514/97, como será exposto a seguir.

\subsection{O ALCANCE DO § 5ํD ARTIGO 27 DA LEI № 9.514/97}

Seguindo a lógica protecionista imposta pelo SFH, a Lei o 9.514/97 estabeleceu regras para a constituição e a execução da garantia obtida mediante a alienação fiduciária de um bem imóvel, sempre atentando ao caráter vulnerável do devedor. Dessa maneira, o art. 27 elenca as fases do procedimento executório ${ }^{5}$, que devem ser seguidas em caso comprovação do inadimplemento do devedor e da necessidade de consolidação da propriedade fiduciária em nome do credor 6 .

No âmbito do SFH, o devedor pretende adquirir a casa própria, mas não foi capaz de pagar as parcelas e juros que Ihe cabiam. Em virtude de seu inadimplemento e posterior consolidação da propriedade, deverá entregar o imóvel à leilão, em atendimento à execução da alienação fiduciária, como forma de cobrir o valor da dívida e ressarcir o credor das despesas acessórias.

Se em um dos dois leilões previstos, o valor auferido for superior ao da dívida, o restante será devolvido ao devedor (art. $27, \S 4^{\circ}$ ).

No $\S 5^{\circ}$ do referido art. 27, o legislador foi além e determinou que, após cumpridos os procedimentos de realização de dois leilões do imóvel a dívida seria considerada extinta, caso não fosse oferecido em nenhum deles valor superior ou igual ao da dívida, somado das despesas, dos prêmios do seguro, dos encargos legais, inclusive tributos, e das contribuições condominiais.

\footnotetext{
${ }^{5}$ Registra-se 0 art. 27 teve sua redação parcialmente alterada pela Lei $n^{0}$ 13.465/2017 (conversão da Medida Provisória $n^{\circ}$ 759/2016). Foi dada nova redação ao parágrafo $1^{\circ}$ e e incluídos os parágrafos $2^{\circ}$ A, $2^{\circ}-\mathrm{B}$ e $9^{\circ}$. Não obstante, persiste a redação originária do parágrafo $5^{\circ}$, cerne da exposição.

${ }^{6} \mathrm{~A}$ mora do fiduciante deve ser comprovada na forma do art. $26, \S 1^{\circ}$. Caso não haja sem a purgação da mora, o oficial do Registro de Imóveis, certificará esse fato e fará a averbação na matrícula do imóvel da consolidação da propriedade em nome do fiduciário, à vista da prova do pagamento por este, do imposto de transmissão inter vivos e, se for o caso, do laudêmio (art. 26, § $7^{\circ}$ ). Em seguida, o fiduciário, no prazo de trinta dias, contados da data do registro da consolidação da propriedade, promoverá público leilão para a alienação do imóvel (art. 27, caput).
} 
Percebe-se que a previsão legislativa de extinção da dívida do fiduciante constitui norma especial, totalmente oposta à orientação do Código Civil quanto à propriedade fiduciária nele regulada. De acordo com o art. 1.366, caso a coisa objeto de propriedade fiduciária venha a ser vendida e seu produto não bastar para o pagamento da dívida e das despesas de cobrança, o fiduciante continuará obrigado pelo saldo.

Exatamente por reconhecer a especialidade da Lei ํo 9.514/97 e seus objetivos, o art. 1.367 do Código Civil ressalva a aplicação "da legislação especial pertinente" para a propriedade fiduciária de bens imóveis.

Pode-se compreender que se o imóvel dado em garantia, em nenhum dos dois leilões legais, receber lance capaz de quitar o débito na sua integralidade (art. 26 , $\left.\S 1^{\circ}\right)$, deverá o credor ficar com a propriedade do bem e dar plena e irretratável quitação ao devedor, nada mais deste podendo cobrar.

A respeito desta imposição legal, comenta Melhim Namem Chalhub (2012, p.264-265):

Com efeito, trata-se de mecanismo compensatório justificado pelo sentido social do crédito habitacional e dele há precedente no direito positivo brasileiro: a Lei no 5.741, de 1971, que institui processo especial de execução de crédito vinculado ao Sistema Financeiro da Habitação, prevê que, não havendo lance que cubra o valor da dívida, dá-se automática adjudicação do imóvel ao credor com a quitação da dívida, operando a adjudicação os mesmos efeitos da dação em pagamento.

Em razão da dação em pagamento do imóvel ao fiduciário em substituição à prestação original, este deverá aceitá-lo e dar por quitada a obrigação do fiduciante. Embora não haja o consentimento necessário do credor disposto no art. 356 do Código Civil, os efeitos e a aplicação são tecnicamente os mesmos previstos para a dação em pagamento.

Com a ampliação da alienação fiduciária para fins de garantir qualquer obrigação, a Lei oㅜ 10.931/04 criou a possibilidade de o credor ser obrigado a dar quitação do saldo não coberto pela venda do imóvel em segundo leilão a qualquer devedor (pessoa física ou jurídica) e não mais apenas ao cidadão vulnerável. Destarte, não há mais a presunção de que as relações das partes envolvidas no contrato seriam não-paritárias e assimétricas. 
Como conclui Melhim Namem Chalub (2012, p.265) em breve explanação sobre o tema:

No que tange à alienação fiduciária sobre bens imóveis, quando da formulação do Projeto de Lei que resultou na Lei no 9.514/97 cogitava-se de sua aplicação restrita ao mercado habitacional, de modo que, em atenção ao grande alcance social desses financiamentos, a lei exonerou o fiduciante da obrigação de pagar o saldo devedor que remanescesse, caso o imóvel fosse levado a leilão e não se alcançasse valor suficiente para resgate da dívida. Sucede que, posteriormente, a Lei no 10.931, de 2004, no seu art. 51, veio a estender a aplicação da alienação fiduciária de bens imóveis para garantia das obrigações em geral, sejam habitacionais ou empresariais, sem, contudo, fazer qualquer ressalva quanto ao perdão da dívida previsto na legislação anteriormente, de modo que, mesmo nos empréstimos destinados a atividades empresariais a empresa devedora ficará exonerada de pagar o saldo devedor, caso não se alcance no leilão valor suficiente para resgatar inteiramente sua dívida.

No mesmo sentido procede a crítica de Milena Donato Oliva (2014, p.114):

\begin{abstract}
Já se observou que o regime diferenciado da alienação fiduciária de imóveis se justificaria para a tutela do mutuário vulnerável no financiamento imobiliário. Nessa direção, a Lei $\mathrm{n}^{\circ}$ 5.741/1971 [art. $7^{\circ}$ ], no âmbito da proteção do financiamento de bens imóveis vinculados ao Sistema Financeiro de Habitação, já previa dispositivo semelhante, o que corroboraria o escopo protetivo e excepcional do preceito. No entanto, a Lei no 10.931/2004, em seu art. 51, estendeu o emprego da alienação fiduciária de coisa imóvel à garantia das obrigações em geral, abrangendo, assim, relações paritárias e não paritárias, de maneira que não procede mais a justificativa inicialmente alvitrada para a exoneração do devedor no que tange o saldo remanescente após a execução da garantia.
\end{abstract}

A grande incongruência reside no fato de a Lei no 10.931/2004 em momento algum ter feito qualquer ressalva sobre como deveria ocorrer o procedimento executório da garantia, caso se evidenciasse que as partes contratantes estão em pé de igualdade uma perante a outra.

Melhim Namen Chalhub (2012, p.256), um dos juristas que colaborou para a elaboração do $\mathrm{PL}$ № 3.242/97, assim se manifestou sobre a problemática ora levantada:

Nada justifica, entretanto, que seja esse benefício estendido ao tomador de financiamento para atividades empresariais ou para outras finalidades nãohabitacionais, nem aos participantes de grupos de autofinanciamento denominado consórcio na linguagem comum. 
Não é plausível que se mantenha a disposição constante no artigo 27 , §5ํㅡㄹ da Lei ํo 9.514/97 aplicável a todos os casos e, consequentemente, na geração de uma condição desfavorável ao financiador. Com esta situação, no longo prazo, o instituto torna-se inseguro devido ao seu alto grau de risco no momento da execução para o credor.

Da maneira como se encontra normativamente estabelecido, abre-se a oportunidade para decisões judiciais que impõem ao financiado, além de arcar com os riscos já inerentes ao empreendimento, suportar os riscos de desvalorização do imóvel no mercado na vigência do contrato. Isso porque, ainda que ocorra qualquer variação que justifique a queda do preço do imóvel, o que motivaria a não obtenção de valor bastante para cobrir o saldo devedor nos leilões, o credor deverá aceitá-lo como quitação total do débito, suportando o saldo remanescente não pago.

Percebe-se que a previsão legislativa, com o fito de criar externalidades positivas ao mercado imobiliário, ao ampliar ilimitadamente as possibilidades de extinção do saldo devedor, trouxe externalidades negativas com potencial impacto direto nos custos de transação do financiador imobiliário. A posição adotada pelo Poder Judiciário, quando reafirma a extensão do benefício e inviabiliza a possibilidade de continuidade da execução em relação ao valor residual, encontra seus fundamentos diretos no modelo normativo vigente, daí a existência de movimentos no sentido de alterá-lo.

\section{PROPOSIÇÕES LEGISLATIVAS PARA ALTERAÇÃO DO § 5 DO ART. 27 DA}

\section{LEI № 9.514/97}

No seio do Poder Legislativo federal também se percebeu a distorção no sistema de financiamento imobiliário por meio de alienação fiduciária de imóveis e a problemática causada pela impossibilidade de execução do saldo remanescente.

Desta forma, serão examinados os Projetos de Lei apresentados na Câmara dos Deputados para alterar a redação do $\S 5^{\circ}$ do artigo 27.

Em maio de 2017, encontravam-se em tramitação na Câmara dos Deputados os PL no 6.525/2013 e o 4.714/2016, ambos de autoria do deputado Carlos Bezerra 
(MT) ${ }^{7}$. Sem embargo, o mesmo deputado já havia apresentado em 2007, o PL no 1.070. O projeto consistiu na primeira tentativa de alteração das incongruências normativas constantes na Lei oㅜ 9.514/97 e consequente atualização deste diploma legal a sua atual aplicabilidade.

O PL № 1.070 pretendia alterar o §5으, do artigo 27, da Lei no 9.514/97 para que sua redação passa a vigorar da seguinte forma:

$\S 5^{\circ}$ - No caso de financiamento de imóvel habitacional, se, no segundo leilão, o maior lance oferecido não for igual ou superior ao valor referido no $\S 2^{\circ}$, considerar-se-á extinta a dívida e exonerado o credor da obrigação de que trata 0 §4으.

Se por um lado a alteração proposta ao texto não tiraria o benefício dado ao devedor vulnerável quando da promulgação da lei em 1997, por outro, limitava a aplicação da remissão legal apenas ao financiamento de imóvel com fins habitacionais.

Além da alteração acima, o PL 1.070 visava também a mudança no $\S 8^{\circ}$ do art. 27, o qual passaria a vigorar com a seguinte redação: "§ $8^{\circ}$ As disposições dos $\S \S$ $5^{\circ}$ e $6^{\circ}$ deste artigo não se aplicam às operações de financiamento não-habitacional e às de autofinanciamento realizadas por grupos de consórcio".

$O$ § 60 do art. 27 refere-se à obrigação do credor em dar quitação ao devedor, no prazo de cinco dias a contar da data do segundo leilão, mediante termo próprio. A proposição de lege ferenda isentaria o credor de financiamento não-habitacional e os consórcios deste procedimento, possibilitando a estes a cobrança de saldo existente.

Como justificação para a alteração da lei, o deputado suscitou os motivos pelos quais esta foi idealizada, relembrando que, no momento de sua instituição, cogitava-se sua aplicação de forma restrita ao mercado habitacional e visando ao alcance social dos financiamentos concedidos nesse âmbito (BRASIL, 2007).

Assim, com a implementação das alterações sugeridas, a lei manteria seu sentido social sem dar benefícios que o extrapolam, decorrentes de um perdão descabido. Ocorre que o Projeto de Lei foi arquivado por término da legislatura em

\footnotetext{
7 O PL no 4.714/2016 foi apresentado em virtude do arquivamento em 2011 do PL no 1.070/2007, propondo também a alteração do mesmo dispositivo legal. O PL 4.714/2016 encontra-se apensado ao PL 6.525/2013, razão pela qual não será comentado.
} 
31/01/2011 e não proporcionou a retomada do progresso na sistematização do instituto da alienação fiduciária de imóvel que propunha.

Em 2013 o mesmo deputado retomou a proposição por meio do PL № 6.525, porém mediante a inclusão de um novo parágrafo no art. contendo a seguinte redação:

\begin{abstract}
$\S$ 9ำ A extinção da dívida e a exoneração do devedor da respectiva obrigação, previstas nos $\S \S 4^{\circ}$ e $5^{\circ}$ deste artigo, aplicam-se tão somente às operações de financiamento imobiliário, não se estendendo, em hipótese alguma, a qualquer outra modalidade de financiamento na qual se utilize contratualmente da alienação fiduciária em garantia.
\end{abstract}

Exaltando as melhorias trazidas pelo advento da Lei ํㅜ 9.514/97 e os avanços no mercado imobiliário brasileiro, com aumento na compra de imóveis, o deputado, mais uma vez, tentou mostrar à Câmara dos Deputados a necessidade de aperfeiçoamento da alienação fiduciária de imóveis, após mais de quinze anos de vigência da Lei.

O PL naㅡ 6.525/13 encontra-se ainda em tramitação na Câmara dos Deputados na Comissão de Desenvolvimento Urbano, com parecer favorável do relator deputado Carlos Marun na forma de substitutivo ${ }^{8}$.

\title{
4 DA INAPLICABILIDADE DO ART. 14, § 6 DA LEI № 11.795/2008 E DA SÚMULA 384 DO STJ AOS CONTRATOS DE ALIENAÇÃO FIDUCIÁRIA DE IMÓVEIS
}

É notório que o processo legislativo para a aprovação de leis ordinárias é lento e as proposições apresentadas podem ser rejeitadas ou arquivadas. Considerandose que a aplicação da norma do art. 27, § 5o, da Lei 9.514/97 é inadmissível fora do âmbito do financiamento imobiliário habitacional, é preciso pensar, dentro do

\footnotetext{
${ }^{8}$ No substitutivo propõe-se o acréscimo à Lei no 9.514/97 do art. 26-A: "Os procedimentos de cobrança, purgação de mora, consolidação da propriedade e leilão relativos aos contratos de financiamento habitacional sujeitam-se às seguintes normas especiais [...] III - Se, no segundo leilão o maior lance oferecido não for igual ou superior ao valor da dívida e seus acréscimos, considerar-se-á extinta a dívida; no prazo de cinco dias a contar da data do segundo leilão o credor dará quitação ao devedor mediante termo próprio". Para os contratos de financiamento não habitacional, na forma da redação de lege ferenda do art. $27, \S 5$ ․ "O devedor continuará obrigado pelo pagamento do saldo remanescente, mediante ação de execução, caso no procedimento de venda do bem não haja oferta de quantia suficiente para pagamento integral da dívida garantida, seus encargos e despesas de cobrança".
} 
instrumental legislativo vigente e sua interpretação pelos Tribunais Superiores, em soluções viáveis.

A exemplo do aperfeiçoamento necessário à legislação atualmente em vigor sobre alienação fiduciária de imóveis, no que tange aos sistemas de consórcios, foi promulgada a Lei ํㅜ 11.795/2008.

Consoante definição do art. $2^{\circ}$ da Lei no $11.795 / 2008$, Consórcio "é a reunião de pessoas naturais ou jurídicas em grupo, com prazo de duração prazo e número de cotas previamente determinados, promovida por administradora de consórcio, com a finalidade de propiciar a seus integrantes, de forma isonômica, a aquisição de bens ou serviços, por meio do autofinanciamento".

Os integrantes do consórcio são tratados de maneira isonômica, todos no mesmo patamar e mediante a formação de um grupo sem privilégios ou diferenciação (art. $3^{\circ}$, $\S^{2} 2^{\circ}$ ). Ao contrário dos financiamentos habitacionais, não cabe, portanto, falar em benefícios embasados na vulnerabilidade de um perante os demais.

Caso fosse aplicado o modelo previsto na Lei o 9.514/97, em caso de execução do imóvel e verificação de saldo remanescente, seria concedido o perdão da dívida ao consorciado e o consórcio suportaria a diferença, com prejuízo para todo um grupo, em prol de apenas um membro responsável pela prestação da garantia. Enxergando a necessidade de suprir esta lacuna, o legislador, incluiu o art. 14, que versa a respeito das garantias exigidas dos consorciados para utilizar o crédito.

O § 6º do art. 14, por sua vez, foi o responsável por trazer a inovação há muito pretendida e ainda não implementada na Lei no 9.514/97.

O oferecedor de garantia por meio de alienação fiduciária de imóvel ficará responsável pelo pagamento integral das obrigações pecuniárias estabelecidas no contrato de participação em grupo de consórcio, por adesão, inclusive da parte que remanescer após a execução dessa garantia. Portanto, caso o imóvel alienado fiduciariamente seja levado à execução e, após cumprido o procedimento previsto na Lei no 9.514/97, se remanescer diferença, o fiduciante deverá cobri-la, realizando o pagamento integral da dívida. Com este expediente, cada membro do consórcio arcará com sua obrigação sem prejudicar os demais, ainda que o imóvel dado em garantia seja insuficiente para cobrir todo o valor do débito. 
Em que pese a previsão da obrigação do consorciado cobrir a diferença e realizar o pagamento integral da dívida, a disposição da Lei no 11.795/2008 não pode ser aplicada aos financiamentos garantidos por alienação fiduciária de imóveis. Justifica-se tal assertiva pelo critério da especialidade, pois a premissa adotada pela Lei dos Consórcios é a paridade entre as partes. Tal pressuposto, como visto, é uma das características do instituto e impõe a impossibilidade de perdão da dívida a um dos consorciados em prejuízo ao consórcio como um todo.

Na Lei no 9.514/97, ao contrário, a premissa adotada para a extinção da dívida em favor do devedor é a vulnerabilidade. A questão não é afastar tal premissa, mas sim limitá-la aos financiamentos habitacionais para aquisição da casa própria dentro de limites máximo de valor do imóvel, para garantir o escopo que motivou a criação da Lei. A aplicação da norma da Lei oㅜ 11.795/2008 poderia aniquilar totalmente $\mathrm{o}$ art. 27 , § $5^{\circ}$ da Lei $n^{\circ} 9.514 / 97$, impedindo que a dívida pudesse ser considerada quitada, inclusive nos casos de vulnerabilidade do devedor.

Outra razão importante para a inaplicabilidade da regra dos consórcios aos financiamentos imobiliários em geral decorre da previsão contida no art. 1.367 do Código Civil de que a propriedade fiduciária de bens imóveis é regulada pela legislação especial pertinente. Desta forma, estaria afastada a disposição do art. 1.366 de que o fiduciante continuará obrigado pelo saldo, mesma orientação da Lei no 11.795/2008.

A constatação supra aumenta ainda mais a importância da necessidade de alteração legislativa, que só virá com a aprovação do PL oㅜ 6.525/2013 pelo Congresso.

Também não seria possível sustentar a admissão da execução judicial do saldo devedor remanescente pelo fiduciário com fulcro na orientação jurisprudencial pacificada exarada na Súmula 384 do Superior Tribunal de Justiça ${ }^{9}$.

A referida súmula está fundamentada legalmente no art. 1.102A do Código de Processo Civil de 1973, correspondente ao art. 700, I, do CPC 2015, que trata das hipóteses de cabimento da ação monitória.

\footnotetext{
9 BRASIL. 2009: "Cabe ação monitória para haver saldo remanescente oriundo da venda extrajudicial de bem alienado fiduciariamente em garantia".
} 
Em simples leitura perfunctória da supracitada súmula, poder-se-ia concluir que incongruência normativa existente no disposto no art. 51 da Lei no 10.931/2004 c/c art. 27, § 5으 da Lei oㅜ 9.514/97 fora sanada por entendimento consolidado do STJ.

Ao permitir a ação monitória para reaver saldo remanescente da venda extrajudicial de bem alienado fiduciariamente, o STJ teria afastado a automaticidade do perdão imposto pela lei e condicionado sua aplicação à análise do caso concreto, solucionando o problema trazido pela ampliação da utilização do instituto proporcionada pela Lei $n^{0} 10.931 / 04$. Contudo, em simples leitura dos precedentes ${ }^{10}$ apresentados como justificativa para edição da Súmula 384, percebe-se que não é o que se infere do texto da súmula o pretendido no momento de sua aprovação.

Pela análise das quatro decisões precedentes para edição da Súmula 384 evidencia-se que, não obstante essa conter em seu texto a expressão "bem alienado fiduciariamente em garantia", sem dispor de maneira clara se se trata de bem móvel ou imóvel, todos os precedentes se referem a vendas extrajudiciais de bens móveis.

A discussão travada no STJ que levou à edição da Súmula 384 se deu em virtude da iliquidez do título após a venda extrajudicial da garantia (veículos). Em havendo alienação extrajudicial do bem móvel, ainda que haja saldo remanescente, o STJ entendeu que esse saldo não pode ser executado de pronto. Isto porque, não é válido que o valor do débito seja unilateralmente declarado pelo fiduciário, sem que haja por parte do fiduciante reconhecimento do valor exato da dívida, depois de descontado o valor obtido na venda do bem alienado e, se for o caso, com a oportunidade para o segundo de apontar erros no cálculo apresentado pelo primeiro.

Ao contrário, na alienação fiduciária de imóveis, a lei especial determina expressamente o perdão do saldo remanescente existente depois da venda do imóvel e o procedimento de cobrança é diverso da alienação fiduciária de bens móveis ${ }^{11}$.

\footnotetext{
10 Nesse sentido, cf. Recurso Especial 끄 2432/CE, Recurso Especial oㅡ 63392/MG, Recurso Especial no 331789/MG, todos julgados pela Quarta Turma e Recurso Especial oㅡ 647002/PR, julgado pela Terceira Turma.

${ }^{11} \mathrm{Na}$ alienação fiduciária de bem móvel, o Decreto Lei no 911/1969, com alteração promovida pela Lei no 10.931/2004, criou a obrigação de que o devedor pague a integralidade da dívida, não havendo perdão ao que remanescer dos valores apresentados pelo fiduciário na inicial, conforme se verifica pela redação do art. $3^{\circ}$, $\S 2^{\circ}$ : "No prazo do $\S 1^{\circ}$ [cinco dias], o devedor fiduciante poderá pagar a integralidade da dívida pendente, segundo os valores apresentados pelo credor fiduciário na inicial, hipótese na qual o bem Ihe será restituído livre do ônus".
} 
Desta forma, a edição da Súmula 384 do STJ apenas corrobora a disparidade do tratamento dado aos credores de alienação fiduciária de bens imóveis, em relação aos bens móveis, e para a necessidade latente de adequação das disposições constantes na Lei ํㅡ 9.514/97, sobretudo do parágrafo $5^{\circ}$ do artigo 27 , por meio de reforma legislativa.

\section{ANÁLISE ECONÔMICA DO REGIME PROTECIONISTA DA LEI № 9.514/97 EM RELAÇÃO AO FIDUCIANTE: COMPORTAMENTOS E NORMAS}

A promulgação da Constituição Federal de 1988 ocorreu no Brasil num momento de transição do regime militar para o restabelecimento pleno da democracia no país. País no qual um percentual significativo de seus cidadãos enquadrava-se nos mais baixos patamares de renda, formando uma massa excluída do pleno acesso a bens e serviços.

Daí a extensão de seus dispositivos, especialmente aqueles voltados aos direitos fundamentais e de ordem social, incluído o direito à propriedade privada (art.5ำ XXII), o que se relaciona diretamente com a generalização do modelo de alienação fiduciária mais benéfica ao adquirente, ao se ter o direito de moradia como direito social corolário do princípio da dignidade da pessoa humana (art. 1ํ, III, c/c art. 6ㅇ).

Os quase trinta anos de vigência da Constituição Federal brasileira, ao mesmo tempo em que se fazem acompanhar de inegável mudança social, apresentam-nos a conta da opção interventiva mais ampla, especialmente no campo da economia: contas públicas negativas, déficit preocupante da previdência, decretação de estado de calamidade financeira em vários Municípios e Estados.

No campo da disciplina da alienação fiduciária e do regime protecionista em relação ao fiduciante, os itens anteriores deste artigo apontam para a necessidade de revisão de sua disciplina normativa ao se cotejar a origem e a função do regime mais benéfico, porém restrito, estabelecido pela lei originária e a sua ampliação posterior.

$\mathrm{O}$ quadro exige do intérprete e estudioso do direito que reconheça que a edição normativa pode ser eficiente, em termos de produção dos efeitos pretendidos, 
em determinado contextos, ou, ainda, estar absolutamente dissociada de suas pretensões. Essa é a base do pensamento de Douglass North.

\subsection{INSTITUIÇÕES FORMAIS E COMPORTAMENTO}

No dizer de Douglass North, no âmbito das teorias que compõe a escola chamada de Nova Economia Institucional, as instituições são as regras do jogo, sejam elas formais ou informais. Dentre as instituições formais, destacam-se as normas jurídicas. As regras do jogo, logo, as instituições, ao mesmo tempo em que levam a uma limitação na autonomia privada devem estar associadas à eficiência, já que os atores ou agentes deixaram de ter um plano ilimitado de decisões possíveis, para estarem condicionados ao que a lei determina (NORTH, 1994, p.360).

Para os institucionalistas, a edição de uma norma, em tese, significa reconhecer que o ordenamento jurídico conhece os seus potenciais efeitos e, por intermédio de uma política de estímulo (normas promocionais) ou de desestímulo (normas punitivas) já sugere ou impõe, respectivamente, o cumprimento de uma determinada conduta.

As normas jurídicas se mostram, sob essa ótica, como instrumentos de eficiência, já que tem a pretensão de redução de tempo e custos associados ao processo de escolha, o que pode ser sintetizado na expressão trade off (NORTH, 1994, p.360).

Sobre a real eficiência da Análise Econômica do Direito, segundo Ivo GICO JR (2016, p.18):

[....] é um movimento que se filia ao consequencialismo, isto é, seus praticantes acreditam que as regras às quais nossa sociedade se submete, portanto, o direito, devem ser elaboradas, aplicadas e alteradas de acordo com suas consequências no mundo real, e não por julgamentos de valor desprovidos de fundamentos empíricos (deontologismo).

Porém, a escolha dos métodos e critérios de aferição de eficiência normativa traz grande dificuldade (MACRAE, 2009, p.255-264).

Ainda, assim, o papel das instituições é reduzir as incertezas e orientar o comportamento, representando um guia para a interação humana (ROCHA, 2016, 
p.164). São as oportunidades criadas pelas instituições, por sua vez, que dão surgimento às organizações. Organizações são grupos de indivíduos vinculados por certos propósitos ou objetivos, enquadrando-se aí tanto o Estado como uma sociedade empresária (WILLIAMSON, 1996, p.361).

As mudanças nas instituições somente ocorrem quando os indivíduos acreditam que podem melhorar sua situação, por meio de mudanças estruturais (WILLIAMSON, 1996, p.361-362). Por outro lado, as mudanças serão para melhor ou não, a depender do conhecimento agremiado pelos indivíduos. É imprescindível identificar a questão a ser modificada e o convencimento do agente político para que seja promovida a alteração que se faz necessária.

A norma jurídica, em seu aspecto meramente formal, à condição de ter sido elaborada a partir de critérios estabelecidos pelo ordenamento jurídico, será vocacionada a dirigir os comportamentos, seja de forma direta, seja pela imposição de sanções. Todavia, no campo de sua aplicabilidade, a norma é vazia de significado se não for acompanhada dos comportamentos que condicionam a sua eficácia. É possível mencionar aqui, por exemplo, a necessidade de monitoramento das condutas tipificadas pela norma, de que efetivamente sirvam de condução ao comportamento humano a partir da premissa legal, seja espontaneamente, seja por coerção.

Logo, norma e comportamento são indissociáveis no campo prático. E, comportamentos, por sua vez, remetem à figura do agente que, utilizando-se de sua racionalidade, de sua necessidade ou de sua paixão, irá escolher a conduta a ser executada. Porém, agentes têm diferentes níveis de racionalidade, sendo equivocado imaginar que agirão sempre de forma maximizadora ou de boa-fé.

Os limites de racionalidade e os desvios à boa-fé permitem que determinados agentes retirem uma vantagem pessoal que desequilibre a relação jurídica, no campo privado, ou caracterize um mau uso da instituição, no campo da incidência normativa. $\mathrm{Na}$ seara privada contratual, a conduta oportunista pode conduzir a que um contrato seja descumprido ou uma relação estável descontinuada. No campo da incidência normativa, as vantagens pessoais acobertadas por um suposto interesse social, para serem coibidas, dependerão de reforma normativa ou da consolidação hermenêutica no sentido da correção na aplicação da norma. 
Uma situação de vantagem pessoal travestida de interesse social pode ser identificada, por exemplo, quando uma norma, no propósito declarado de minimizar danos ambientais, estabelece multas aplicáveis nas situações indesejadas, mas que, em razão do proveito econômico real do empresário na dada situação concreta, acaba por consolidar a prática infratora que se repete, já que o proveito é maior do que a sanção.

Assim é que, infelizmente, normas podem produzir efeitos indesejáveis desde a sua origem, ou em razão do contexto na qual estão sendo aplicadas ter sofrido modificações. Os efeitos negativos podem, por sua vez, decorrer de um comportamento oportunista do agente, ou serem o reflexo de um comportamento não desejado ou pensado pelo legislador quando disciplinou a matéria, ou pelo agente público, quando tomou a decisão administrativa.

\subsection{EFEITO PELTZMAN VIS-À-VIS A EXONERAÇÃO DO FIDUCIANTE}

O chamado Efeito Peltzman pode ser invocado quando uma decisão normativa ou administrativa produz um resultado que não havia sido pensado quando de sua edição. Efeito negativo decorrente de uma conduta de relaxamento das partes sujeitas ao efeito da norma ou decisão. No episódio constatado pelo economista Sam Peltzman, a duplicação de uma ponte (decisão administrativa) acabou por produzir um aumento no número de acidentes naquela ponte. No entanto, a opção pela duplicação havia sido pautada exclusivamente no propósito de melhorar a eficiência para os usuários do percurso, não para ser uma concausa no aumento do índice de sinistros (SHIKIDA, 2016, p.40)

Se a pretensão da ação era o aumento do bem-estar, o fato de ter aumentado o número de acidentes graves sinaliza para uma distorção, ou seja, para a formação do efeito Peltzman. Uma determinada norma (exatamente como se dá no caso da limitação da responsabilidade do fiduciante, nos termos artigo 27 , §5ํㅡ, da Lei $n^{\circ}$ 9.514/97) pode atingir o reverso de sua pretensão inicial.

Tome-se o exemplo de uma norma muito rigorosa que imponha um limite de velocidade em uma dada rodovia: há a possibilidade de que seja destinada à diminuição no número de acidentes, ou, prestar-se somente ao objetivo de 
maximização da receita governamental; ou, no tema deste artigo, a limitação da responsabilidade do fiduciante, independentemente de faixa de preço do imóvel e de sua condição social, pode restringir, encarecer ou eliminar o crédito indispensável para a incorporação de novas construções de moradia. A eliminação pode se dar precisamente em relação aos agentes que se queria proteger, os mais carentes. A restrição, por sua vez, pode refletir em face dos potenciais adquirentes de unidades habitacionais voltadas à classe média e alta, sem qualquer benefício para os destinatários originais no âmbito do SFH.

Um dos grandes problemas na intervenção por meio da norma jurídica reside justamente nos efeitos indesejáveis que podem dela recorrer, seja desde a sua origem, ou a partir de um dado momento histórico. Dissonância entre os objetivos que nortearam a norma editada e outros efeitos que dela decorrem involuntariamente.

Como já visto neste artigo, no caso do regime da alienação fiduciária, a exposição de motivos da norma originária estabeleceu claramente a função a que se destinava a sua sistemática de excepcionalização. A norma jurídica foi concebida para limitar a obrigação do fiduciante, mediante a retirada da possibilidade de o fiduciário continuar a execução para além do valor do bem alienado: a proteção do menos favorecido, como parte da política de acesso à casa própria.

A mesma limitação, agora projetada para qualquer contrato de alienação fiduciária, perde a conexão com o objetivo e com o contexto de sua criação, o que deve justificar a sua revisão, sob pena de o objetivo inicial do legislador quando de seu estabelecimento afastar-se indelevelmente da prática.

Aliás, sob o aspecto econômico, a depender da capacidade de endividamento do devedor e da possibilidade de acesso à informação do credor, a doutrina debate até que ponto a simples existência de créditos mais privilegiados do que outros, por força de lei, pode impactar negativamente no mercado de crédito. Existirá o risco de os credores não garantidos/privilegiados aumentarem seus juros (associados ao spread) de forma desproporcional à redução associada ao estabelecimento de garantias (SHUPACK, 1989).

Partindo-se do pressuposto de que as normas devem ser ponderadas, para além da teoria expressa em sua redação, ganha destaque a necessidade de identificação da conveniência da intervenção normativa, assim como a possibilidade 
de que processos de revisão sejam desencadeados a fim de promover-se adequações, quando necessário.

\title{
5.3 CONTRIBUIÇÃO DA ANÁLISE ECONÔMICA DO DIREITO PARA A CONSTRUÇÃO NORMATIVA
}

Os autores optaram por não desenvolver um pensamento teórico prévio acerca da Análise Econômica do Direito- AED. No entanto, em cada um de seus tópicos, a forma de argumentação do artigo está respaldada em metodologia sugerida pela AED. Uma análise consequencialista do sistema que disciplina a alienação fiduciária.

A análise desenvolvida perpassa não apenas pela identificação dos fatores que levaram à edição da Lei no 9.514/97, como também pelas propostas de modificação deste sistema, de forma a se reconhecer o desvirtuamento na aplicação generalizada do tratamento favorecido ao adquirente de bens imóveis pela via da alienação fiduciária. A revisão proposta tem por proposito, ainda, a preservação do regime de financiamento de bens imóveis de cunho de moradia. A impossibilidade sistemática de recuperação do valor financiado tem por inequívoca consequência, senão o desaparecimento desta linha de financiamento, o seu encarecimento generalizado. Diante do quadro relatado, ou os agentes financeiros reduzem esta linha de crédito ou farão incidir sobre as demais linhas o custo do risco de perda de parcela do valor oferecido no financiamento.

A AED pode ser invocada em sua vertente normativa ou positiva. A análise positiva volta-se ao estudo das normas editadas, a fim de se aquilatar a eficiência ou não das normas existentes e a análise normativa sugere que, apuradas as carências ou ineficiências, sejam sugeridas modificações no sistema normativo.

Segundo Ivo Gico Jr (2016, p.18):

\begin{abstract}
A Análise Econômica do Direito (AED), portanto, é o campo do conhecimento humano que tem por objetivo empregar os variados ferramentais teóricos e empíricos econômicos e das ciências afins para expandir a compreensão e o alcance do direito e aperfeiçoar o desenvolvimento, a aplicação e a avaliação de normas jurídicas, principalmente com relação às suas consequências.
\end{abstract}


Os impactos do aspecto econômico no Direito vão muito além das considerações sobre custos de transação ou eficiência. Os efeitos econômicos, pelo fato de transbordarem para o mercado, podem fazer com que determinada norma se torne ineficiente, desabilitando-a aos seus propósitos com impactos de ordem social.

Assim é que o direito constitucionalmente assegurado à propriedade e a política habitacional podem trazer determinações legais que, em sua aplicabilidade, acabam por produzir efeitos indesejáveis ou pouco eficientes, não apenas em termos econômicos, mas igualmente sociais.

Para Ivo Gico Jr. (2010):

\begin{abstract}
A AED tem por característica a aplicação da metodologia econômica a todas as áreas do direito, de contratos a constitucional, de regulação a processo civil, de direito ambiental a família e é justamente essa amplitude de aplicação que qualifica uma abordagem AED da simples aplicação de conhecimentos econômicos em áreas tradicionalmente associadas à economia.
\end{abstract}

Há duas alternativas para aquele que pensa o Direito. Satisfazer-se com a vigência da norma, considerar que nada mais há a fazer para o aprimoramento da vida em sociedade, ou, aceitar o desafio de considerar o contexto da edição normativa, a sua aplicabilidade no decorrer do tempo, para assinalar e propor eventuais modificações com o propósito de aprimoramento da vida em sociedade, inclusive valendo-se das ferramentas da Análise Econômica do Direito.

\title{
CONCLUSÃO
}

Como parte de uma política habitacional voltada à oferta de aquisição de bens imóveis para moradia e diante da não sustentabilidade do programa nacional pautado na utilização de recursos oriundos das cadernetas de poupança e do FGTS, foram editadas normativas que estimularam a utilização do regime de financiamento pela via do contrato de alienação fiduciária em garantia na aquisição de bens imóveis.

Com o propósito de favorecer os adquirentes de imóveis de baixa renda, no âmbito do Sistema Brasileiro de Habitação, foram crescentes os descompassos entre o valor efetivamente devolvido pelo fiduciante ao fiduciário, fortalecidos pelas políticas 
voltadas à antecipação de parcelas para quitação ou ainda, pela desconformidade entre o valor total das parcelas pagas e a recuperação do valor investido e de sua remuneração comparativamente ao mercado. Como proposta de solução foram consolidadas estratégias que operaram por meio da criação e utilização de fundos garantidores para os referidos contratos de financiamento.

Todavia, as formas de intervenção do Estado na economia, especialmente quando voltadas a condutas que impactam no mercado, o deficit no sistema financeiro da habitação e sua relativa insustentabilidade no longo prazo, produziram limitações na oferta de crédito habitacional e estimularam a busca por outros mecanismos de financiamento, e como visto, a alienação fiduciária em garantia ganhou espaço.

Ainda com o propósito de salvaguarda dos adquirentes de imóveis de baixa renda, a Lei disciplinadora da alienação fiduciária imobiliária prevê limitações à responsabilidade do fiduciante, pois, atendidas as condições e os processos estabelecidos na Lei, este não responde mais perante o fiduciário pela diferença entre o valor obtido na venda do bem (executado) e o valor da obrigação.

O que foi pensado, conforme demonstrado pela exposição de motivos da normativa aqui analisada, para estimular o acesso ao bem imóvel de moradia para o adquirente de baixa renda, acabou sendo repassado para qualquer aquisição de bem que se processe pela via da alienação fiduciária em garantia.

A AED permite que se identifique a necessidade de modificação de normativas, como a ora analisada, seja porque a jurisprudência firmada não resolve o impasse produzido pela generalização do sistema protetivo, seja porque há consequências indesejáveis que decorrem inevitavelmente da generalização do benefício. Os efeitos estão consubstanciados na potencialidade de redução de oferta de financiamento pela via da alienação fiduciária justamente para os adquirentes de baixa renda, seja pela projeção das potenciais perdas do fiduciante na oferta de financiamento para outras faixas de adquirentes, mediante aumento dos juros.

As normas, instituições formais, são modelos de comportamento estabelecidos e dotados de força coercitiva que encontram a sua razão de ser na sua vocação à produção de resultados economicamente e socialmente eficientes.

Quando o conteúdo normativo produz efeitos indesejáveis, o que pode ocorrer em decorrência das normas estarem relacionadas a comportamentos, e esses não 
serem necessariamente aqueles esperados pelo legislador - pela carência de informação do agente ou por deliberada atuação oportunista- ocorre um afastamento entre a pretensão e o resultado. O afastamento pode ser resultado também da modificação do contexto social que emoldurou a construção normativa e aquele do momento de sua aplicação.

Desta forma, o legislador brasileiro já identificou a necessidade de alteração da normativa aplicável à alienação fiduciária em garantia na aquisição de bens imóveis. Sem embargo, é preciso implementá-la, de forma a delimitar o tratamento excepcional que hoje permite, de forma generalizada, a impossibilidade de o fiduciário buscar o pleno ressarcimento pelo valor inadimplido pelo fiduciante.

A efetiva alteração da norma analisada é medida necessária para a correção do atual sistema de forma a superar-se a inadequação do regime vigente.

\section{REFERÊNCIAS}

ALVIM NETO, José Manoel de Arruda. Alienação Fiduciária de Bem Imóvel: O Contexto de Inserção do Instituto em Nosso Direito e em Nossa Conjuntura Econômica, Revista de Direito Privado. São Paulo. n.2. p. 147-76. abr./jun. 2000.

AZEVEDO, Álvaro Villaça. Alienação Fiduciária em Garantia de Bem Móvel e Imóvel. Revista da Faculdade de Direito da Fundação Armando Álvares Penteado. São Paulo. v.1. n.1. p. 61-84. 2002.

BEALE, Hugh Secured Transactions, 14 Juridica Int'l 96 (2008). Disponível em HeinOnline. Acesso 27/1/2018.

\section{BRASIL. Código de Processo Civil.}

. Lei no 9.514, de 20 de novembro de 1997. Disponível em: http://www.planalto.gov.br/ccivil 03/LEIS/L9514.htm.

. Súmula 384. Aprovada em 27/05/2009 e publicada no Diária da Justiça eletrônico de 08/06/2009. Disponível em: https://ww2.stj.jus.br/docs internet/revista/eletronica/stj-revista-sumulas201335 capSumula384.pdf.

PL

1070/2007.

Disponível em: https://www.camara.leg.br/proposicoesWeb/fichadetramitacao?idProposicao $=351552$ Acesso 09/06/2017. 
CANUTO, Elza Maria Alves. Alienação Fiduciária de Bem Móvel. 4.ed. Belo Horizonte: Del Rey, 2003.

CHALHUB, Melhim Namem. Negócio Fiduciário. 4.ed. Rio de Janeiro: Renovar, 2009.

. Alienação Fiduciária. Incorporação Imobiliária e Mercado de Capitais. 3.ed. Rio de Janeiro: Renovar, 2012.

CUMYN, Madeleine Cantin. Reflexiones Autour de la Diversite des Modes de Reception ou d'Adaptation du Trust dans les Pays de Droit Civil, 58 McGill L. J. 811(2013). Disponível em HeinOnline. Acesso 2/2/2018.

DANTZGER, Afranio Carlos Camargo. Alienação Fiduciária de Bens Imóveis. 3.ed. São Paulo: Método, 2010.

FUCCl, Paulo Eduardo. Aspectos da Alienação Fiduciária de Coisa Imóvel. Revista dos Tribunais. São Paulo. v. 87. n.753. p.80-3. jul. 1998.

GICO JR, Ivo Teixeira. Introdução à análise econômica do direito. In: RIBEIRO, Marcia Carla Pereira; KLEIN, Vinícius (Coord.). O que é análise econômica do direito: uma introdução, 2 ed.. Belo Horizonte: Fórum, 2016.

Metodologia e Epistemologia da Análise Econômica do Direito. Economic Analysis of Law Review, v. 1, no 1, Jan-Jun, 2010. Disponível em: $<$ http://portalrevistas.ucb.br/index.php/EALR/article/view/1460/1110>. Acesso 09/06/2017.

GILMORE, Grant. The Secured Transactions Article of the Commercial Code (1951). Faculty Scholarship Series. Paper 2558. Disponível em http://digitalcommons.law.yale.edu/fss_papers/2558. Acesso 02/02/2018

LOUREIRO, José Eduardo. Alienação Fiduciária de Coisa Imóvel. Revista do Advogado. São Paulo. n. 63. p. 86-95. jun. 2001.

MACRAE, Donald. Análise de Impacto Regulatório - AIR: a experiência do Reino Unido. Regulação e Agências Reguladoras: governança e análise de impacto regulatório. RAMALHO, Pedro Ivo S. (org.), Brasília: Anvisa, 2009. pp. 255-264.

MARTINS, Rodrigo Sanz. A Necessidade de Instituição de Mecanismo de Controle Judicial Prévio de Consolidação da Propriedade Fiduciária de Bem Imóvel. Revista Forense. Rio de Janeiro. v.107. n. 413. p. 683-93. jan/jun. 2011.

NORTH, Douglass C. Economic performance trough time. The American Economic Review. vol. 84, n. 3, jun., 1994

OLIVA, Milena Donato. Do Negócio Fiduciário à Fidúcia. São Paulo: Atlas. 2014. 
PETERSON, Christopher L.. Predatory Structured Finance, 28 Cardozo L. Rev. 2185 (2007). Disponível em HeinOnline. Acesso 2/2/2018.

ROCHA, Eduardo de Assis Brasil. Algumas Considerações sobre a Alienação Fiduciária de Coisa Imóvel. Revista de Direito Imobiliário. São Paulo. v.21. n.45. p. 95-103. set/dez. 1998.

ROCHA, Lara Bonemer Azevedo da; RIBEIRO, Marcia Carla Pereira. Eficiência e Justiça. In.: Análise econômica do direito: justiça e desenvolvimento. RIBEIRO, Marcia Carla Pereira. et. all. Curitiba: CRV, 2016.

SANTOS, Ernani Fidelis dos. Alienação Fiduciária de Coisa Imóvel. Revista Jurídica. Porto Alegre. v. 47. n. 261. p. 21-4. jul. 1999.

SHIKIDA, Claudio. Efeito Peltzman. In.: Análise econômica do direito: justiça e desenvolvimento. RIBEIRO, Marcia Carla Pereira et. all (org.). Curitiba: CRV, 2016, p. 40-46.

SHUPACK, Paul. Solving the Puzzle of Secured Transactions. 41 Rutgers L. Rev. 1067 (1989). Disponível em HeinOnline. Acesso 2/2/2018. 